\title{
DESIGN AND DEVELOPMENT OF SOLAR POWERED STIRLING ENGINE FOR ELECTRICITY GENERATION
}

\author{
MAYUR PATIL ${ }^{1} \&$ C S CHOUDHARI ${ }^{2}$ \\ ${ }^{I} P G$ Student, Department of Mechanical Engineering, AISSMS COE, Pune, India \\ ${ }^{2}$ Assistant Professor, Department of Mechanical Engineering, AISSMS COE, Pune, India
}

\begin{abstract}
In recent year's requirement of electrical energy is very high. In this paper design and development of Stirling engine based on green energy application is discussed. A medium capacity i.e. 55 cc Swept volume engine is required to be designed and developed based on Stirling engine principles. This engine is going to be tested by using helium as a working fluid design consideration for this engine having helium as a heat source is fixed within the temperature range of 600-650 ${ }^{\circ} \mathrm{C}$ and the range of charge pressure is 0-10 bar. Reflective type aluminium foil parabolic solar collector is used to harness the solar energy. This is used as heating medium for helium gas. It is expected to deliver maximum power output of $24 \mathrm{~kW}$-hr/day with helium at $650^{\circ} \mathrm{Cheat}$ source temperature and 10 bar charge pressure. $24 \mathrm{~kW}$-hr/day is basic energy consumption of single house. Development of such Stirling engine for domestic purpose is considered as primary design criteria. This Stirling engine will play to whiter roll in overall pollution control and energy conservation.

KEYWORDS: Gamma type, Helium working fluid, Scheffler's dish, Stirling cycle \& Stirling engine
\end{abstract}

Received: Jul 21, 2020; Accepted: Aug 10, 2020; Published: Sep 14, 2020; Paper Id.: IJAUERDDEC20201

\section{INTRODUCTION}

Now a days, requirement of reliable and efficient renewable energy sources is on high demand. In this study, paper has described and discussed design and development of Stirling engine based on green energy approach. Energy conservation and effective energy utilization are main aspects for the natural resources. However, their depletion is ongoing day by day with mass level utilization. As a part of external combustion engines category, Stirling engines are operable with wide range of heat applications. Energy conservation in different applications is possible by preferring Stirling engine.

While working on closed cycle prime mover, Robert Stirling invented the first Stirling engine and patented it during 1817. Even then, many similar engines came with different forms. Mechanical power is generated from the solar power due to conversion aided by Stirling cycle with high efficiency. Ideally, Stirling cycle is followed in which two isochronal and two isothermal processes are included. Compressible fluids like hydrogen, air, helium, nitrogen, vapours constitute working fluid. Concentrating solar power systems incorporated Stirling engines with mirrors arrangement. Due to cheap and simpler construction, developing countries can benefit themselves with this kind of power source with economical advantage. Different configurations and designs have been studied and reviewed literature.

In solar modules, Scheffler's Dish, three stages needed to convert solar energy into electricity. Initial stage involves aluminium foil parabolic reflector is focused to heat pipe due to which radiation is converted to heat. While the second stage, heat is converted to mechanical energy. Third stage is related to electricity generation from 
this mechanical energy with the help of device such as generator. Collector efficiency is total percentage of energy transformed by solar radiation to heat. Thermal efficiency is defined by energy transformed heat to mechanical energy. Final alternator efficiency is defined by mechanical energy converted electricity respectively. The overall efficiency is defined by efficiency of light transformed to electricity efficiency. As the overall efficiency is the measure of the light energy to electricity conversion within complete system. Parker and Malik have carried out several investigations related to solar energy during sixties. With that experimentation, Fresnel lens, a light absorber and Stirling engine are used. Potassium and sodium based eutectic mixture converted the heat from absorber to heater by evaporation in absorber. Condensation takes on the heater head.

Can Cinar and Halit Karabulut [1], studied gamma type of Stirling engine with manufacturing and testing included in it. The prototyped Stirling engine was with $276 \mathrm{cc}$ swept volume. Electric furnace was used in that experiment as a heat source, and helium and air as an agent. Heat range included was 700 to 1000 degree Celsius for obtaining working characteristics while the pressure range found as $1 \mathrm{bar}$ to $4.5 \mathrm{bar}$. With the eater cooled arrangement, the system given with $0.464 \mathrm{~W}$ power per cc swept volume. Non-significant difference was found at furnace and heater head temperature points. Stirling engine has given double power due to presence of helium within system.

Shendage D.J et al. [2] has also studied one Stirling engine system. In that, $1.5 \mathrm{Kw}$ capacity was marked for electrical output. Solar concentrator delivering the heat to the receiver and flame was generated. The overall heat found $705 \mathrm{~K}$ at the experiment. Laboratory setup was tested with heaters. The beta configuration was present with one cylinder, rhombic pressure operating with hydrogen as working fluid pressure at $30 \mathrm{bar}$ and $1440 \mathrm{rpm}$. While temperature ranges found $350 \mathrm{~K}$ to $750 \mathrm{~K}$. The efficiency estimated by this experiment was $37 \%$.

\section{STIRLING ENGINE POWER PLANT}

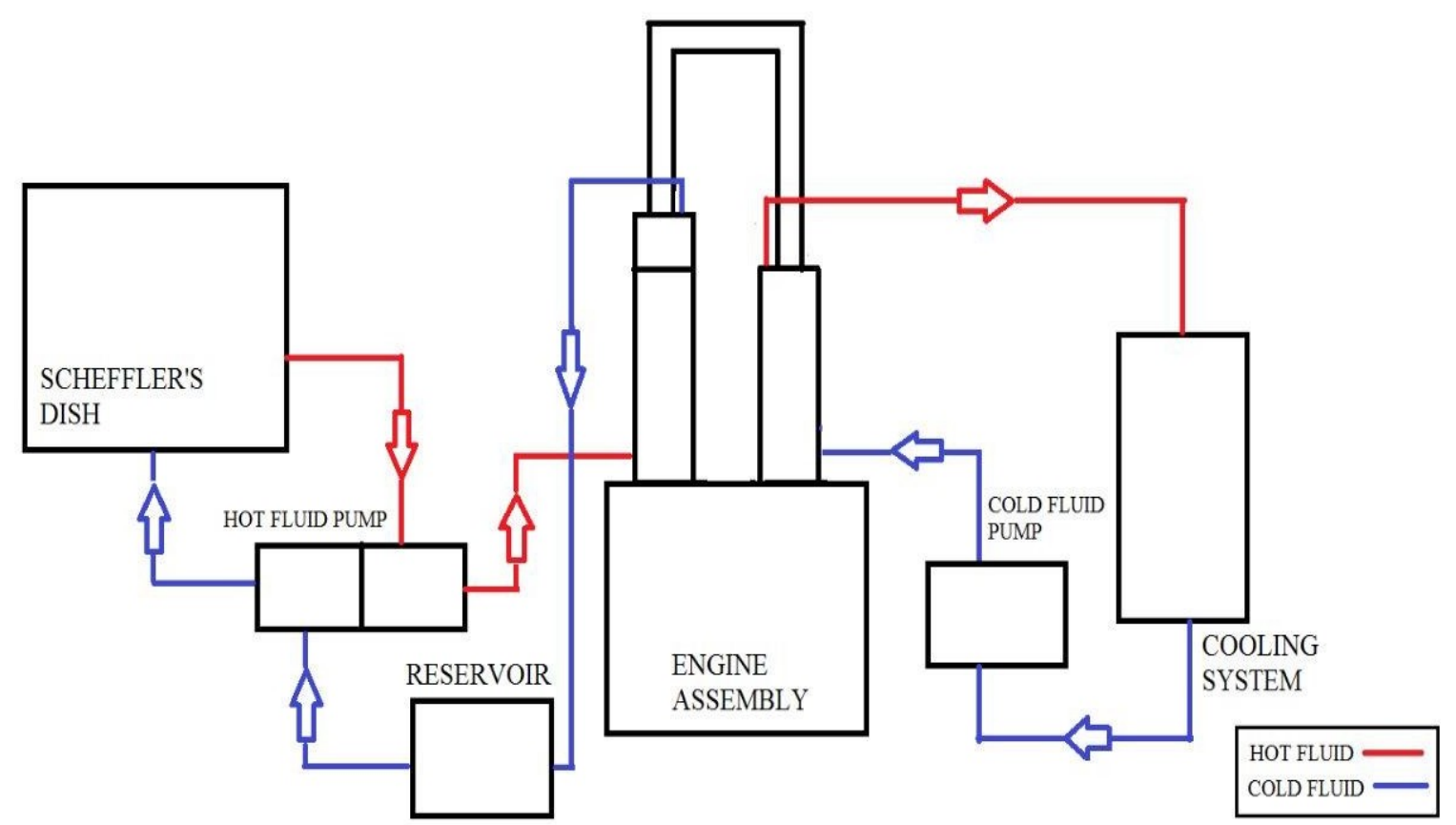

Figure 1: Schematic Stirling Engine Power Plant

Heat Source: The heat source consists of eutectic mixture based on sodium and potassium. Engine related internal 
parts will not have any reaction due to this mixture. The fuel mixture is solely used for providing combustion phenomenon at the Stirling engine cycle. As the main requirement is that the working fluid should not mix with helium content.

Heater / Hot cylinder: For smaller, mid-range engines walls of hot space are sufficient. But in case of larger applications, greater surface area is an advantage for engine. Hot cylinder is fitted with an internal spring structure which guides hot fluid circulation by which working fluid will get heated. It has piston cylinder arrangement with two specific hot and cold cylinder assembly.

Regenerator: Regenerator is heat exchanging device which slightly store heat in between cold and hot side of cylinders. The working fluid is managed to pass from one side and then other side as well as exchanging heat through return cycle. The major advantage for providing such arrangement is to add more thermal efficiency by effect of heat recycling close loop phenomenon with irreversible manner. With the help of such arrangement, it is possible to gain more power output with increased thermal efficiency.

Cooler / cold cylinder: Cold cylinder consists of the cooling arrangement which converts high temperature working fluid to the cold working fluid. Larger area is needed to transfer sufficient amount of heat from walls. Cold working fluid can be transferred to hot side with the help of piston arrangement.

Displacer/ Piston: The major part of the Stirling engine includes displacer which transfers the working fluid across the hot and cold side. The fluid can be transferred across regenerator. The sealing arrangement at displacer totally depends on engine design, type and application. For the current setup experiment, sealed displacer is used.

\section{STIRLING ENGINE CYCLE}

Stirling engine works on Stirling cycle which comprises of four processes. These are shown in Fig 2

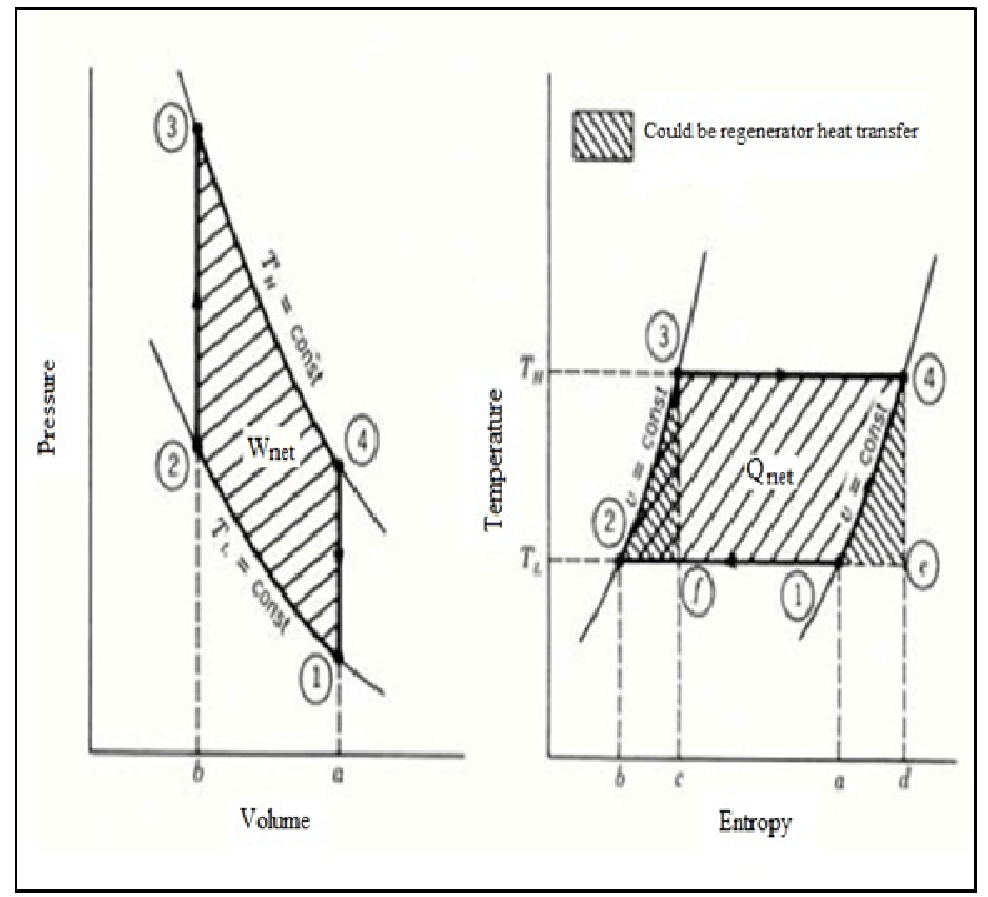

Figure 2: Stirling Engine Cycle 
- $\quad$ Process 1( Isothermal compression):

Helium as working fluid is compressed at constant temperature. Heat [Q (1-2)] = area 1-2-b-a on T-s diagram Work is done on the working fluid. $\mathrm{W}(1-2)=$ area $1-2-b-a$ on P-v diagram.

\section{- $\quad$ Process 2-3 (Isochoric heat addition):}

Heat is added at constant volume to the hot cylinder. Heat [Q (2-3)] = area 2-3-c-b on T-s diagram Work done [W (2-3)] is zero.

\section{- $\quad$ Process 3-4 (Isothermal expansion):}

Working fluid is expanded at constant temperature. Heat $[\mathrm{Q}(3-4)]=$ area 3-4-d-c on T-s diagram Hot air expands Work is done by the working fluid $\mathrm{W}(3-4)=$ area $3-4-\mathrm{a}-\mathrm{b}$ on $\mathrm{P}-\mathrm{v}$ diagram

- $\quad$ Process 4-1 (Isochoric heat rejection):

Heat id rejected at constant volume to the cold cylinder. Heat $[Q(4-1)]=$ area 1-4-d-a on T-s diagram.

\section{METHODOLOGY}

- Selection of material for various parts of Stirling engine depending upon its application.

- Design of individual parts.

- Manufacturing of Stirling engine.

- $\quad$ Assemble all the parts of Stirling engine and check.

- Take a trial on Stirling engine and check the flow of working fluid.

- Observed the flow of helium gas fluid and minimise the errors in assembly

- Final take trial and check output.

\section{WORLING OF STIRLING ENGINE}

In this Stirling engine, the parabolic Scheffler's dish is used as parabolic reflector which reflects usable $70 \%$ of solar radiation to receiver while only $30 \%$ of heat is been absorbed as we are using dish of Aluminium Foil plating. We are setting the three dishes in such a manner that the solar radiation from each dish will concentrate on separate receiver. The receivers are arranged in series so that the total radiation will heat up the eutectic fluid. The temperature of Thermic fluid will rise up to $650^{\circ} \mathrm{C}$. 


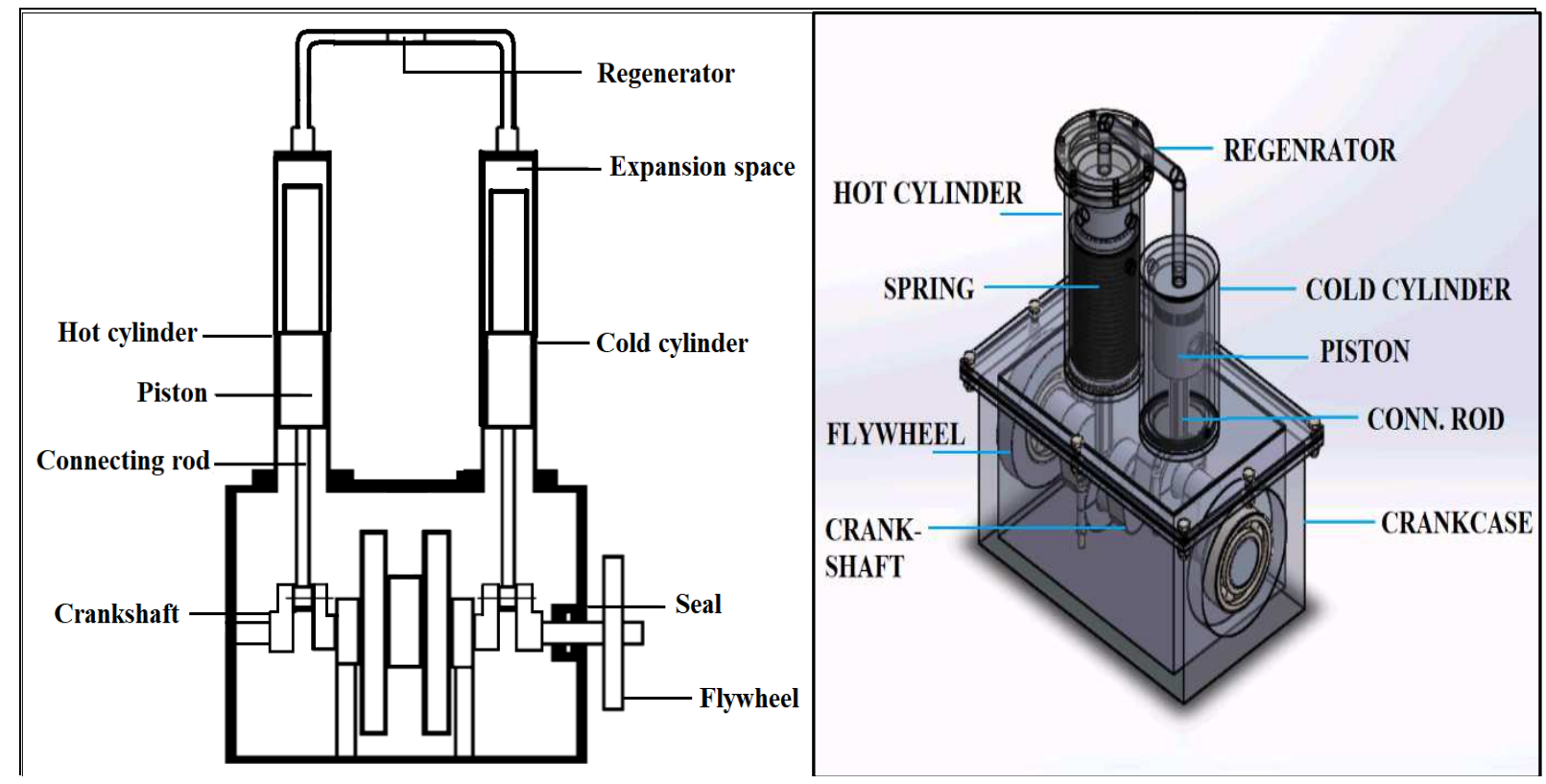

Figure 3: Stirling Engine

The eutectic fluid is stored in a storage tank. Now the hot Thermic fluid mixture is pump out to the hot cylinder where the fluid is guided by a passage created in the jacket. In the cylinder, we are using Helium gas as a working fluid. The helium gas absorbs the heat of Thermic fluid and gets expands to the cold cylinder. In cold cylinder, we are using water cooling method for cooling purpose. When the heated helium is passed in the cold cylinder, the piston will reach to BDC. Now, in cold cylinder the hot helium gas is been cooled by the surrounded water, which results in the compression of piston from BDC to TDC again. The changes in gas temperature causes the corresponding change in gas pressure, while the motion of piston causes the gas to be alternately compress and expand. In this process, in sterling engine, the heat energy is converted to the mechanical power by means of continuous compression and expansion of piston. The flywheel is installed on the crankshaft which stores the mechanical power. Further, this mechanical power is converted to electricity by the generator. In this process, the gas always passes through the regenerator absorbing heat from hot gas and adding it when cooled gas goes back to hot cylinder. Regenerator may be insulated

\section{STIRLING ENGINE SPECIFICATIONS}

The engine type used for construction is Gamma type Stirling engine. The working fluid used is compressed helium gas. The working characteristics of engine will be obtained within the range of heat source temperature ranging from $600-650$ ${ }^{\circ} \mathrm{C}$ and the range of charge pressure $0-10$ bar and other details of the engine are as given below in table 1.

Table 1: Engine Specifications

\begin{tabular}{|l|c|}
\hline \multicolumn{1}{|c|}{ Design Parameters } & Specifications \\
\hline Engine Type & Gamma Type \\
\hline borex stroke & $40.4 \times 43.17$ \\
\hline Working Fluid & Compressed Helium Gas \\
\hline Heated temperature, $\mathrm{T}_{\mathrm{E}}$ & $650^{\mathbf{0}_{\mathrm{C}}}$ \\
\hline Cooled temperature, $\mathrm{T}_{\mathrm{C}}$ & $6 \mathbf{0}^{\mathbf{0}} \mathrm{C}$ \\
\hline Heat Sources & Scheffler's Dish (Solar collector) \\
\hline Cooling method & Water cooling \\
\hline Cylinder material & $\begin{array}{c}\text { SS 304 for Hot cylinder } \\
\text { Aluminium for Cold cylinder }\end{array}$ \\
\hline
\end{tabular}




\section{CONCLUSIONS}

Developed engine would be the better option for electricity generation, especially at domestic and local level. Use of waste heat is quite possible for electricity generation, thereby avoiding environmental pollution.

Developed Sterling engine considering specifications of $50 \mathrm{cc}$ moped is expected to produce electrical power of $0.5 \mathrm{Kwh}$. Use of Helium as a working fluid, avoiding flammable hydrogen and air with poor thermal properties as a result, is the one of the major silent features of this engine. Performance and ease in manufacturing are the major benefits with the development of gamma Sterling engine when compared with alpha and beta sterling engine.

In-house manufacturing of the engine and all the major components like piston, crankshaft, and hot and cold cylinder helped to develop methodology to be used for the development of Sterling engine for power generation with lesser damage to the environment. This work would be highly innovative way of electricity generation in view of sustainable development.

\section{PHOTOS}

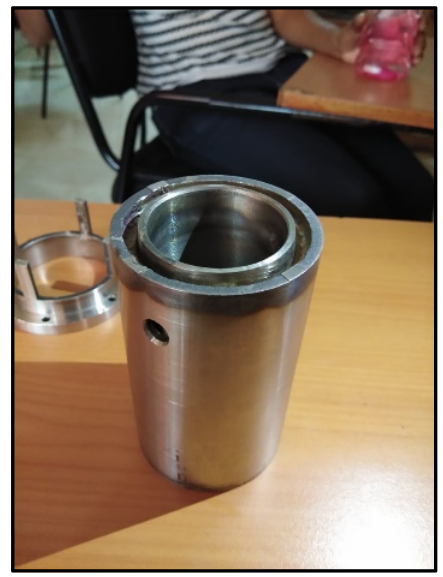

Figure 4: Hot Cylinder

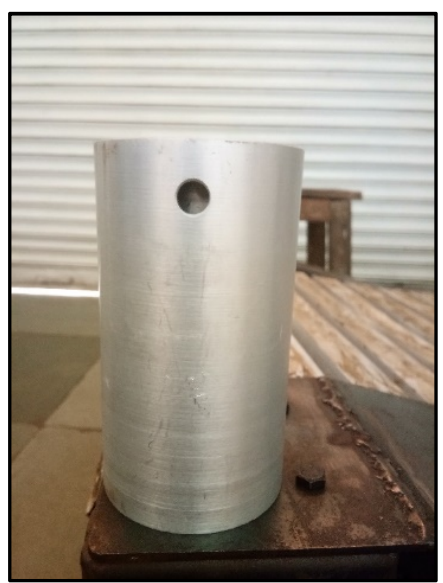

Figure 5: Cold Cylinder

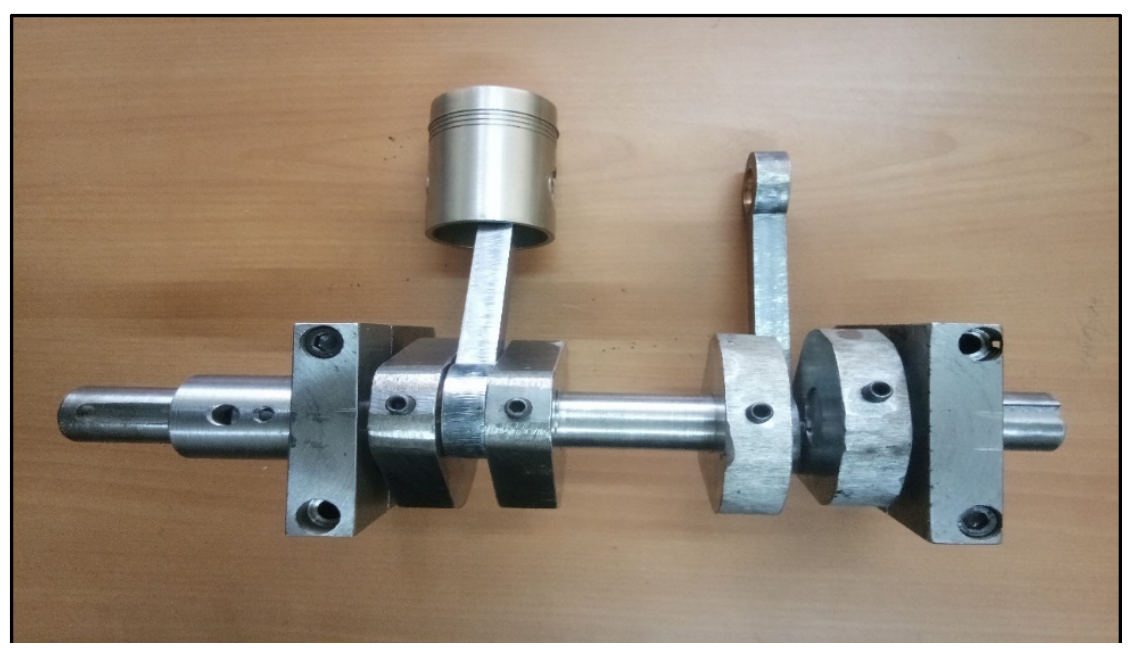

Figure 6: Crankshaft 


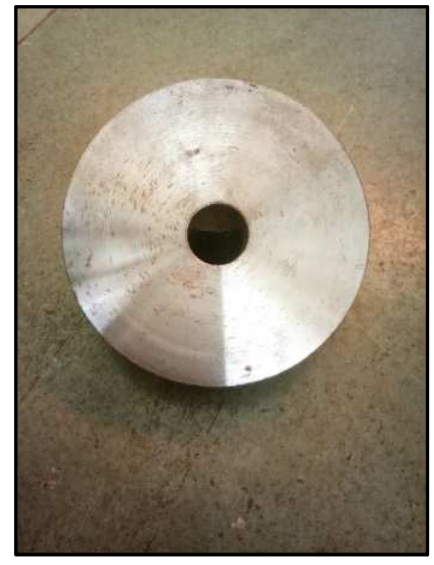

Figure 7: Flywheel

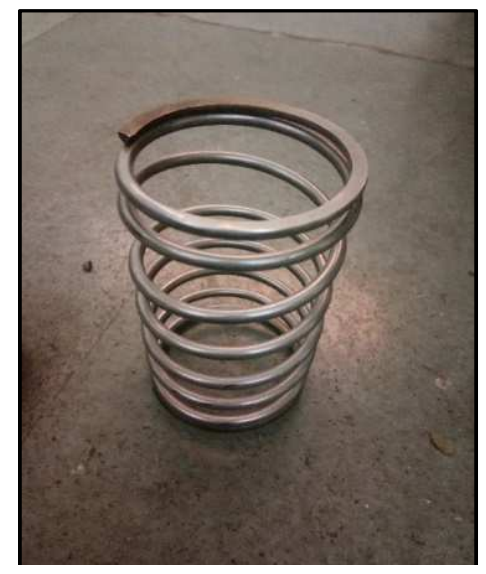

Figure 8: Spring

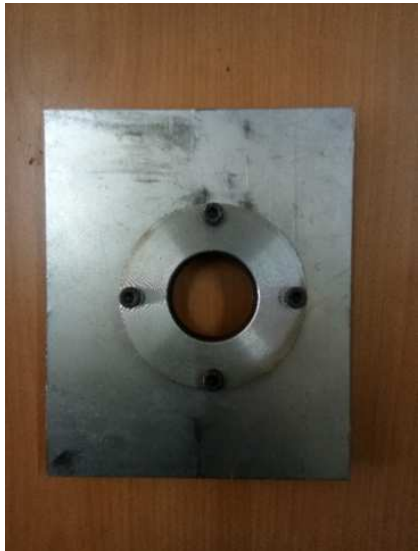

Figure 9: Crank Case Side Plate with Seal

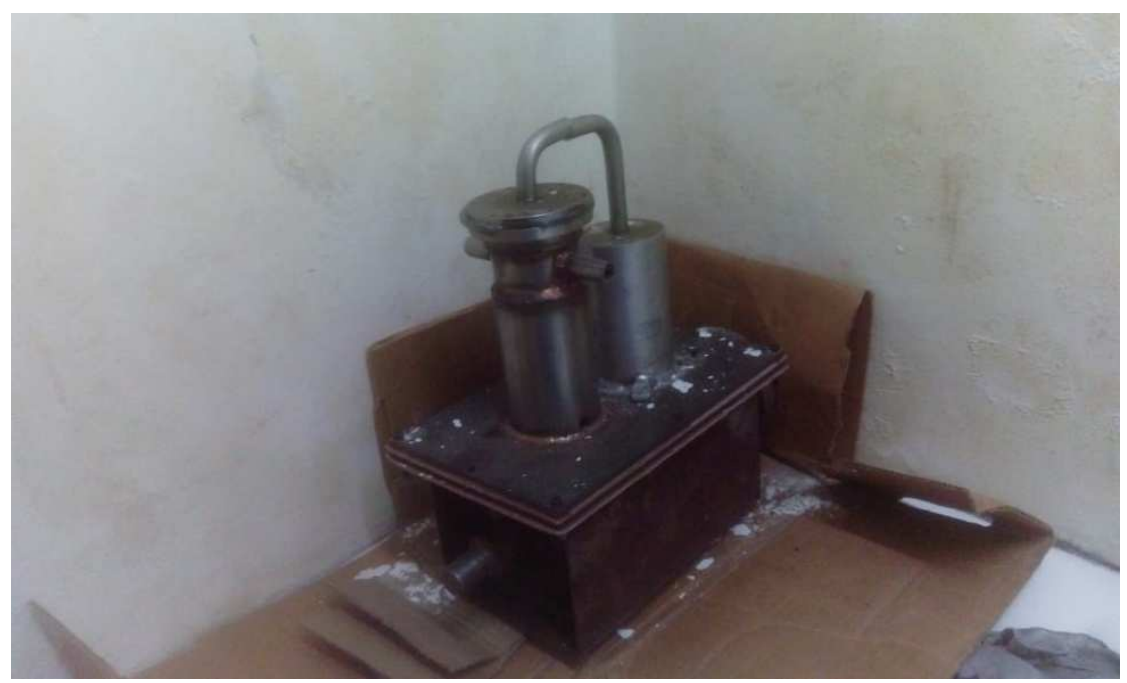

Figure 10: Stirling Engine

\section{ACKNOWLEDGMENT}

The authors are grateful to Mr. Kiran Nawathe (Engineering Cluster, Pune) for proving guidance throughout the project. I would like to thank Engineering Cluster, Pune for financially assisting this project. I would like to thank my father and mother for their continuous support.

\section{REFERENCES}

1. Can Cinar, Halit Karabulut. "Manufacturing and testing of a Gamma type Stirling engine” Renewable Energy 30 (2005) $57-$ 66.

2. Shendage D .J. "Design and Development of Stirling Engine”. Indian Institute of Technology Bombay, Powai, Mumbai $n$ at: https://www.researchgate.net/publication. Accepted October 2015.

3. SUNDAR, R. "NEW CONTROL METHODS IN STIMULATING DRIVE FOR POWER GENERATION IN MARINE APPLICATION." International Journal of Mechanical and Production Engineering Research and Development (IJMPERD)8.1, Feb 2018, 829-834 
4. H. Karabulut*, C. Çınar, E. Ozturk, H.S. Yucesu, "Torque and power characteristics of a helium charged Stirling engine with a lever controlled displacer driving mechanism”, Renewable Energy 35 (2010) 138-143.

5. Hussein, OMAR ASAAD, and PV RAMANA Rao. "Fault Location and Isolation Using Multi Agent Systems in 16 Buses Distribution System." International Journal of Electrical and Electronics Engineering Research 6 (2016): 21-38.

6. Dinesh. k, Gowtham Raj R, Naresh M, Rakesh N, Sriram.R, "Design and Fabrication of Low Cost Stirling Engine for Low Duty Industrial Applications”, International Journal of Scientific and Technology Research Volume3, ISSUE3, ISSN $2277-$ 8616.

7. Ajay Ashok, Arundas S, Bestin Varghese, Ajithkumar.K.T; Design And Fabrication Of Gamma-Type Stirling Engine With Rotary Displacer; International Journal of Research in Engineering and Technology; EISSN: 2319-1163

8. Patil, Bhagyashree, and Maruti Limkar. "Machine to Machine Communication Based Electricity Monitoring and Billing System." International Journal of Electrical and Electronics Engineering Research (IJEEER) ISSN (P) (2016).

9. Hongling Chen, Shawn Czerniak, Enrique De La Cruz, William Frankian, Gary Jackson, Alula Shiferaw, Evan Stewart: Design of a Stirling Engine for Electricity Generation.

10. Sharma, Gangaraju Srinivasa, MVS Murali Krishna, and D. N. Reddy. "CFD analysis for adaptability of producer gas for power generation in gas turbines." International Journal of Mechanical and Production Engineering Research and Development (IJMPERD) 5.2 (2015): 21-32. 